\title{
Computer-Aided Telephone Support for Primary Care Patients with Common Mental Health Conditions: Randomized Controlled Trial
}

Salaha Zaheer ${ }^{1}$, BSc (Hons), MPH; Vanessa Garofalo ${ }^{1}$, BA; David Rodie ${ }^{2,3}$, MD; Athina Perivolaris ${ }^{2}$, RN, MN; Jenny Chum $^{1}$, BSc (Hons); Allison Crawford ${ }^{2,3}, \mathrm{MD}, \mathrm{PhD}$; Rose Geist ${ }^{3,4}, \mathrm{MD}$; Andrea Levinson ${ }^{2,3}, \mathrm{MD}, \mathrm{MSc}$; Brian Mitchell ${ }^{5}$, MD, MSc; David Oslin ${ }^{6}$, MD; Nadiya Sunderji ${ }^{3,7}$, MD, MPH; Benoit H Mulsant ${ }^{2,3}$, MD, MS; PARTNERs Study Group $^{2}$

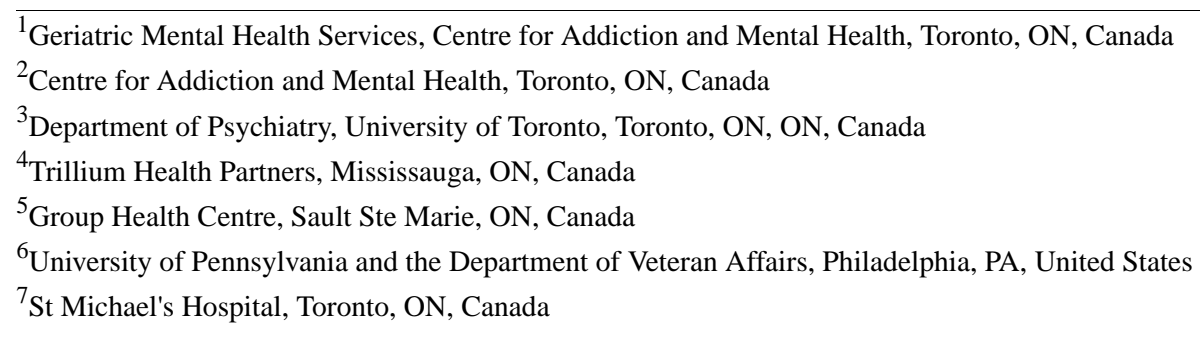

\section{Corresponding Author:}

Benoit H Mulsant, MD, MS

Department of Psychiatry

University of Toronto

Centre for Addiction and Mental Health

250 College Street, Room 835

Toronto, ON, ON, M5T 1R8

Canada

Phone: 14165358501

Fax: 14169796928

Email: benoit.mulsant@utoronto.ca

\section{Abstract}

Background: Depression, anxiety, and at-risk drinking are highly prevalent in primary care settings. Many jurisdictions experience geographical barriers to accessing mental health services, necessitating the development and validation of alternative models of care delivery. Existing evidence supports the acceptability and effectiveness of providing mental health care by telephone.

Objective: This analysis assesses patient's acceptability of computer-aided telephone support delivered by lay providers to primary care patients with depression, anxiety, or at-risk drinking.

Methods: The Primary care Assessment and Research of a Telephone intervention for Neuropsychiatric conditions with Education and Resources study is a randomized controlled trial comparing a computer-aided telephone-based intervention to usual care enhanced by periodic assessments in adult primary care patients referred for the treatment of depression, anxiety, or at-risk drinking; no part of the study involves in-person contact. For this analysis, the following data were obtained: reasons provided for declining consent; reasons provided for withdrawing from the study; study retention rate; and a thematic analysis of a satisfaction survey upon study completion.

Results: During the consent process, $17.1 \%$ (114/667) patients referred to the study declined to participate and $57.0 \%$ of them (65/114) attributed their refusal to research-related factors (ie, randomization and time commitment); a further 16.7\% (19/114) declined owing to the telephone delivery of the intervention. Among the 377 participants who were randomized to the 1-year intervention, the overall retention rate was $82.8 \%$ (312/377). Almost no participants who withdrew from the study identified the telephone components of the study as their reason for withdrawal. Analysis of a qualitative satisfaction survey revealed that $97 \%$ (38/39) of comments related to the telephone components were positive with key reported positive attributes being accessibility, convenience, and privacy. 
Conclusions: Our results suggest that a computer-aided telephone support is highly acceptable to primary care patients with depression, anxiety, or at-risk drinking. In particular, these patients appreciate its accessibility, flexibility, and privacy.

Trial Registration: ClinicalTrials.gov NCT02345122; https://clinicaltrials.gov/ct2/show/NCT02345122 (Archived by WebCite at http://www.webcitation.org/73R9Q2cle)

(JMIR Ment Health 2018;5(4):e10224) doi: 10.2196/10224

\section{KEYWORDS}

telemedicine; collaborative care; depression; anxiety; at-risk drinking; lay provider; family medicine; general practice; primary care psychiatry

\section{Introduction}

\section{Background}

In Canada, 1 in 5 individuals report experiencing symptoms of substance abuse and mental health problems each year [1,2], and almost $75 \%$ of mental health visits are related to mood and anxiety disorders [3].The economic impact of depression alone is estimated to be over Can $\$ 32$ billion, which is twice the amount of money spent on mental health and community care [4]. In Ontario, $15 \%$ of adults have consulted a family physician or a psychiatrist about their mental health in the past year, and mental health visits represent $10 \%$ of all physician visits [5]. More of these visits occur in the primary care settings than in the psychiatric setting [5,6]. Despite the increased focus on mental health, an estimated 1.6 million Canadian citizens report that their needs for mental health were unmet with $36 \%$ reporting that their needs for counseling services were either unmet or partially met [7]. In a recent survey, wait times to see a psychiatrist ranged from 15 to 59 weeks, and wait times to start psychotherapy ranged from 3 to 22 weeks [8].

\section{Prior Work and Rationale}

With long wait times and unmet needs for mental health service, alternative approaches to service delivery have been proposed and evaluated. A literature search was conducted to identify relevant examples of studies that investigated the feasibility and impact of using lay coaches to provide mental health management and support over the phone [9-18]. These studies conducted in the United States or Canada used telephone coaching to provide a range of interventions as follows: self-help resources, symptom tracking, promotion of behavioral activation and self-management, or treatment adherence. Their main findings are summarized in Table 1. Collectively, these studies suggest the acceptability and efficacy of offering support and care via telephone to primary care patients with depression, anxiety, or at-risk drinking. These studies were identified with PubMed using the following keywords: "lay coach," "telephone support," "mental health," "depression," "anxiety," and "alcohol use." We included studies that were judged to be most relevant and met the following criteria: use of a telephone component; use of a lay coach; and focus on depression, anxiety, or alcohol use. Not all interventions described in these studies were successful for all patients. Thus, we are conducting a study to assess the feasibility and impact of a computer-aided telephone-based intervention for primary care patients with depression, anxiety, or at-risk drinking: the Primary care Assessment and Research of a Telephone intervention for Neuropsychiatric conditions with Education and Resources study (PARTNERs; ClinicalTrials.gov Identifier: NCT02345122). PARTNERs utilizes Mental Health Technicians (MHT; coaches) who provide mental health support to patients over the telephone with the help of standardized questionnaires and assessment reports available on the Behavioral Health Laboratory (BHL) software (Capital Solutions, PA, USA). This paper evaluates the acceptability of this intervention and potential limitations from the patient's perspective. 
Table 1. Summary of most relevant published studies of telephone-based support for depression, anxiety, or at-risk drinking.

\begin{tabular}{lll}
\hline Study and location & Study design & Main findings \\
\hline $\begin{array}{l}\text { Simon et al (2000) [9], } \\
\text { United States (n=613) }\end{array}$ & $\begin{array}{l}\text { Patients starting antidepressant trial randomized to 3 } \\
\text { groups: (1) usual care; (2) telephone contacts every 3 } \\
\text { months with feedback only; and (3) telephone contacts } \\
\text { every 3 months with feedback and support. }\end{array}$ & $\begin{array}{l}\text { Patients who received telephone feedback and support } \\
\text { were more likely to receive an adequate antidepressant } \\
\text { dosage; have lower depression scores; and have a }\end{array}$ \\
& $\begin{array}{l}\text { lower likelihood of persistent major depression. } \\
\text { Feedback only had no significant effect on the out- } \\
\text { comes. }\end{array}$ &
\end{tabular}

Oslin et al (2003) [10], United States $(\mathrm{n}=97)$

Brown et al (2007) [11], United States $(\mathrm{n}=819)$

McCusker et al (2012) and Simco et al (2015) [12,17], Canada $(\mathrm{n}=63)$
Veteran participants $(\mathrm{n}=97)$ with depression and at-risk drinking were assigned to 2 groups: (1) usual care and (2) $\mathrm{TDM}^{\mathrm{a}}$ by a behavioral health specialist. Patients in the TDM received regular follow-ups for $24 \mathrm{wk}$. Symptomatic outcomes were assessed at 4-months.

12-month randomized comparison of a telephone intervention and a mail intervention for primary care patients $(\mathrm{n}=819)$ with alcohol use disorders. Participants received telephone counseling (motivational interviewing) or pamphlets on healthy lifestyle. Drinking levels were measured after 3 months.

Open, noncontrolled design. Participants with comorbid depression and chronic physical illness received self-care tools and telephone support by a lay coach for 6 months.
United States $(\mathrm{n}=285)$

Pickett et al (2014) [14],

United States $(\mathrm{n}=124)$

McCusker et al (2015) and McClusker et al (2017) $[15,16](n=223)$
Mello et al (2013) [13],
Injured adults screening positive for alcohol use and discharged from an emergency room randomized to 2-call phone intervention or usual care. Outcomes were measured after 12 months.

12-wk randomized trial of telephone-facilitated depression care and usual care in recently discharged primary care patients.

Randomized trial of a depression self-care tool kit, with and without telephone coaching in primary care adults with depression and comorbid chronic physical condition. Outcomes were measured after 3 and 6 months.
- TDM was associated with improved outcomes for depression and at-risk drinking: response rates were $39 \%$ in the TDM group and $18 \%$ in the usual care group.

- Larger reduction in alcohol consumption was observed in the telephone group than in the mail group (males: $17.3 \%$ vs $12.9 \%$; females: $13.9 \%$ vs $11.0 \%$ )

- The number of telephone counseling sessions was associated with the reduction in drinking.

- The telephone intervention was found to be feasible and acceptable: $91 \%(57 / 63)$ of the participants completed the 2-month follow-up; 63\% (mean 5.7/9) of possible calls were completed.

- Participants experienced significant improvement in depression symptoms at 6 months.

- Alcohol-related injuries were lower in the phone intervention group with no difference in consumption and other alcohol-related consequences.

- No significant difference in outcomes between facilitated and routine care.

- $\quad 77.1 \%$ completed the 6 -month assessment.

- $\quad$ PHQ- $9^{\mathrm{b}}$ scores were significantly different after 3 months but not after 6 months.

- The benefit of coaching on 6-month PHQ-9 was seen only among participants who were not receiving baseline psychological treatment.

- No significant differences in secondary outcomes (self-efficacy, satisfaction, and use of health services).

Rollman et al (2017) [18], Patients with anxiety randomized to a telephone-delivered $\mathrm{CC}^{\mathrm{c}}$ intervention or usual-care referral. Participants in the $\mathrm{CC}$ group received help from a nonmental health professional for 12 months. health-related quality of life, anxiety symptoms, and mood at the 12-month follow-up compared with usual care.
- $\quad$ Patients randomized to $\mathrm{CC}$ had improved mental

\footnotetext{
${ }^{\mathrm{a}}$ TDM: telephone disease management.

${ }^{\mathrm{b}} \mathrm{PHQ}-9$ : Patient Health Questionnaire-9 [19].

${ }^{\mathrm{c}} \mathrm{CC}$ : collaborative care.
}

\section{Methods}

\section{Setting}

PARTNERs is a randomized controlled trial that aims to assess the feasibility and impact of computer-aided telephone monitoring and support for primary care patients with depression, anxiety, or at-risk drinking using an integrated care model. As of April 30, 2017, the project has been implemented at 18 primary care sites, comprising 189 primary care providers
(PCPs; ie, family physicians and nurse practitioners) in urban, suburban, and rural settings across Ontario.

\section{Participants Eligibility and Recruitment}

Starting in November 2014, PCPs identified adult patients with symptoms of depression, anxiety, or at-risk drinking; obtained their verbal permission to refer them to the study; and completed a brief referral form including the patient's phone number and preferred time of contact. Research associates (RAs) called these patients within 5 business days and obtained their consent 
to participate via phone, following a process approved by the Research Ethics Board of the Centre for Addiction and Mental Health (CAMH). Starting with this call and at the beginning of each call, participants were asked to confirm their date of birth to verify their identity. Participants were then scheduled for a baseline assessment to confirm that they met all the inclusion criteria (receiving care from a PCP; referred to the study by their PCP because of depression, anxiety, or at-risk drinking; age 18 years and older; access to a telephone; willingness and ability to converse in English by telephone; willingness and ability to provide informed consent). Participants were excluded if they met one of the following exclusion criteria: psychotic disorder; bipolar disorder; obsessive-compulsive disorder; post-traumatic stress disorder; current substance use disorder except for alcohol use disorder; cognitive impairment as defined by a score of 16 or higher on the Blessed Orientation Memory Concentration test [20]; high risk for suicide; physical condition requiring hospitalization; or expected to die during the next 6 months.

\section{Assessments}

Participants were called by an RA at baseline and after 4,8 , and 12 months and completed a comprehensive assessment using the BHL software. Additional data were obtained regarding reasons for declining to participate in the study, reasons for withdrawing from the study, and satisfaction with participation. Patients who declined consent were asked for their reason(s) and their answers were recorded in a tracking log. Patients who consented but subsequently withdrew before completing the baseline assessment were also asked for their reason(s). When participants withdrew later during the study, reasons were similarly obtained and recorded.

During the 12-month follow-up assessment, participants completed a satisfaction survey including 5 open-ended questions ("Do you have any comments about access or entry to services?"; "Please comment on aspects of your experience with this treatment or support service that were particularly helpful to you"; "Please comment on aspects of your experience with this treatment or support service that you feel could be improved"; and "Any additional comments?") and one 4-point global rating of the services provided (ie, poor, fair, good, and very good). The satisfaction survey was completed by telephone using a REDCap (Vanderbilt University, Nashville, Tennessee with ongoing support from the US National Institutes of Health) database.

\section{Intervention}

After completing the baseline assessment, eligible participants were randomized to either usual care plus research assessments and telephone support ("the intervention") or usual care enhanced by the research assessments ("enhanced usual care").

Using electronic faxes, PCPs were provided with the results of the 4 research assessments for all participants and were contacted as needed clinically (eg, if a participant reported some suicidality). In addition, participants randomized to the intervention received telephone calls from an MHT; typically, these phone calls took place weekly at the initiation of the intervention and tapered off to monthly as participants improved. This decision was based on remission of symptoms as defined by a score of $<10$ on Patient Health Questionnaire- 9 or a decrease of $50 \%$ compared with the baseline score: after remission was maintained for at least 1 month, the frequency of the calls was reduced from weekly to biweekly; after remission was maintained for at least another month, the frequency of the calls was decreased to monthly. The first phone call lasted about 1 hour and the subsequent phone calls lasted 20-30 minutes; all calls were scheduled at times convenient to the participant, including evenings but not weekends. MHTs were bachelor-level trained lay providers. Their main role was to support participants' self-management by monitoring symptoms and treatment adherence, providing education on contributory lifestyle factors, facilitating healthy lifestyle, and communicating updates and recommendations to their PCP [21]. MHTs also facilitated goal setting using a stages-of-change model and motivational interviewing techniques to set Specific; Measurable; Attainable; Relevant; Timely goals. MHTs received weekly supervision from the project psychiatrist.

\section{Data Analysis}

This analysis is based on all data collected until April 30, 2017. Descriptive statistics characterize the participants.

For this analysis, the main measures of acceptability of the telephone-based intervention were as follows: the proportion of referred patients who declined to consent or withdrew before completing the baseline and identified telephone services as their reason for doing so and the overall retention rate. In addition, a content analysis of the qualitative information in the consent tracking log and the satisfaction survey was conducted to characterize the intervention acceptability. Reasons for declined consent and withdrawal prior to completing the baseline were combined. Responses to the overall satisfaction rating and the 4 open-ended questions from the satisfaction survey were analyzed; responses that included comments related to the telephone component of the project were categorized and counted.

\section{Results}

\section{Flow and Characteristics of Participants}

Figure 1 summarizes the flow of the 667 patients who were referred to the study; of these, $10.3 \%$ (69/667) could not be contacted, $0.1 \%(1 / 667)$ had been deemed incompetent to consent; $14.8 \%$ (99/667) declined to consent, and an additional $2.2 \%(15 / 667)$ consented but withdrew before completing the baseline. Moreover, $4.8 \%$ (32/667) could not be contacted to complete the baseline assessment, resulting in 64.3\% (429/667) who completed the baseline assessment. The demographic and clinical characteristics of these 429 participants are presented in Table 2. Of the participants who completed their baseline assessment, $87.9 \%$ (377/429) were randomized, of whom 2 died, 44 withdrew before completing the study, and 19 could not be reached for their 12-month assessment, yielding an overall retention rate of $82.8 \%$ (312/377). 
Figure 1. Flow of participants (November 1, 2014 to April 30, 2017).

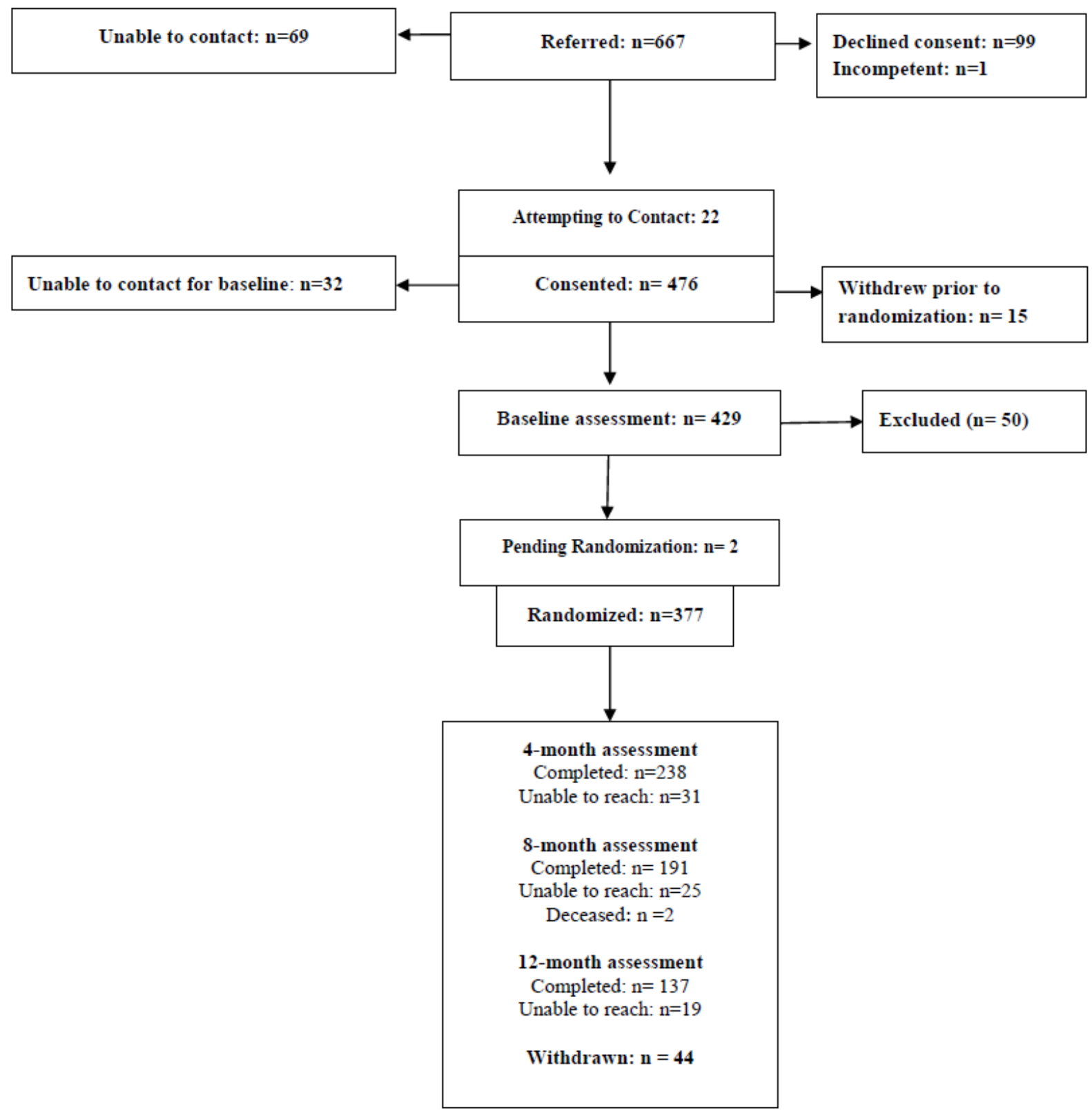

\section{Reasons Provided for Declining Participation in the Study}

Of the participants who declined consent $(n=99)$ or withdrew prior to the baseline assessment $(n=15), 15$ did not provide any reasons for their refusal. Of the 121 reasons provided by the other participants that are presented in Table 3, only $15.7 \%$ $(19 / 121)$ were explicitly related to concerns with the telephone component of the project or to a preference to see a therapist in person.

\section{Reasons Provided for Withdrawing from the Study}

Of the 44 participants who withdrew from the study after being randomized, 10 did not provide a reason for their withdrawal.
The 41 reasons provided by other participants are shown in Table 4; none were attributed to the telephone intervention.

\section{Satisfaction Survey}

The overall satisfaction ratings are presented in Figure 2. In open-ended responses, 39 participants made 45 comments on the use of the telephone in the study (Table 5). Moreover, $16 \%$ (7/45) of these comments were negative and 84\% (38/45) were positive, emphasizing the accessibility and convenience of telephone calls (ie, being able to speak with someone from their home) or the privacy and relative anonymity of the calls. 
Table 2. Characteristics of the 429 participants who completed the baseline assessment.

\begin{tabular}{|c|c|}
\hline Characteristic & Value \\
\hline \multicolumn{2}{|l|}{ Age (years) } \\
\hline Mean (SD) & $41.7(15.8)$ \\
\hline Median (range) & $38(18-90)$ \\
\hline Q1-Q3 & $29-54$ \\
\hline \multicolumn{2}{|l|}{$\operatorname{Sex}, \mathbf{n}(\%)$} \\
\hline Female & $294(68.5)$ \\
\hline \multicolumn{2}{|l|}{ Ethnicity, n (\%) } \\
\hline White & $344(80.2)$ \\
\hline Asian/Pacific Islander & $29(6.8)$ \\
\hline Native Canadian & $16(3.7)$ \\
\hline Black/African Canadian & $15(3.5)$ \\
\hline Other/Mixed & $25(5.8)$ \\
\hline \multicolumn{2}{|l|}{ Self-reported general health, n (\%) } \\
\hline Excellent & $24(5.6)$ \\
\hline Very good & $86(20.0)$ \\
\hline Good & $188(43.8)$ \\
\hline Fair & $98(22.8)$ \\
\hline Poor & $33(7.7)$ \\
\hline \multicolumn{2}{|l|}{ Education, n (\%) } \\
\hline Less than high school & $35(8.2)$ \\
\hline High school graduation & $88(20.5)$ \\
\hline Some college or university & $163(38.0)$ \\
\hline University degree & $102(23.8)$ \\
\hline Postgraduate degree & $34(7.9)$ \\
\hline Other & $7(1.6)$ \\
\hline \multicolumn{2}{|l|}{ Employment, n (\%) } \\
\hline Full-time & $162(37.8)$ \\
\hline Part-time & $63(14.7)$ \\
\hline Not working & $204(47.6)$ \\
\hline \multicolumn{2}{|l|}{ Marital status, n (\%) } \\
\hline Married or partnered & $186(43.4)$ \\
\hline Never married & $166(38.7)$ \\
\hline Divorced or separated & $57(13.2)$ \\
\hline Widowed & $20(4.7)$ \\
\hline \multicolumn{2}{|l|}{ Patient Health Questionnaire-9 } \\
\hline Mean (SD) & $14.0(6.0)$ \\
\hline Minimal (0-4), n (\%) & $19(4.4)$ \\
\hline Mild (5-9), n (\%) & $84(19.6)$ \\
\hline Moderate (10-14), n (\%) & $130(30.3)$ \\
\hline Moderately severe (15-19), n (\%) & $106(24.7)$ \\
\hline Severe (20-27), n (\%) & $90(21.0)$ \\
\hline Generalized anxiety disorder & \\
\hline
\end{tabular}




\begin{tabular}{ll}
\hline Characteristic & Value \\
\hline Mean (SD) & $11.6(5.5)$ \\
Minimal (0-4), $(\%)$ & $45(10.5)$ \\
Mild (5-9), $\mathrm{n}(\%)$ & $115(26.8)$ \\
Moderate (10-14), $\mathrm{n}(\%)$ & $130(30.3)$ \\
Severe (15-21), n (\%) & $139(32.4)$ \\
Alcohol use & \\
At-risk drinker ${ }^{\mathrm{a}}$ & $156(36.4)$ \\
Number of weekly standard drinks, mean (SD) & $7.2(12.8)$ \\
Median (range) & $2(0-113)$ \\
Q1-Q3 & $0-9$ \\
\hline
\end{tabular}

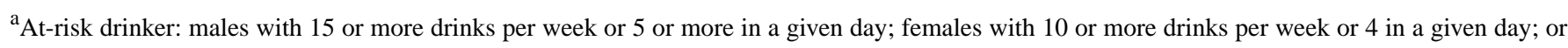
participants endorsing 2 or more symptoms of The Diagnostic and Statistical Manual of Mental Disorders, Fifth Edition Alcohol Use Disorder.

Table 3. Reasons given for declining consent or withdrawing prior to completing the baseline assessment.

\begin{tabular}{|c|c|}
\hline Reasons & Number of times reason was given $(\mathrm{n}=121)^{\mathrm{a}}, \mathrm{n}(\%)$ \\
\hline Concerns with telephone components or prefers in-person assessment and treatment & $19(15.7)$ \\
\hline Concerns with other research components & $65(53.7)$ \\
\hline Time commitment $(30)^{\mathrm{b}}$ & $\mathrm{N} / \mathrm{A}^{\mathrm{c}}$ \\
\hline Not a good fit $(11)^{b}$ & N/A \\
\hline Privacy concerns $(9)^{\mathrm{b}}$ & N/A \\
\hline Concerns with research participation or design (8) & N/A \\
\hline \multicolumn{2}{|l|}{ Communication and logistic barriers $(7)^{b}$} \\
\hline Moving (4) ${ }^{\mathrm{b}}$ & N/A \\
\hline Language or hearing problems $(2)^{\mathrm{b}}$ & N/A \\
\hline Unavailable during study times $(1)^{\mathrm{b}}$ & N/A \\
\hline Prefers or already pursuing other treatment & $18(14.9)$ \\
\hline Does not believe treatment is needed & $15(12.4)$ \\
\hline Feeling better $(14)^{\mathrm{b}}$ & N/A \\
\hline Not interested in seeking help $(1)^{b}$ & N/A \\
\hline Other reasons & $4(3.3)$ \\
\hline
\end{tabular}

${ }^{\mathrm{a}} 121$ reasons provided by 99 patients who declined consent and 15 who withdrew prior to completing the baseline assessment (some provided multiple responses).

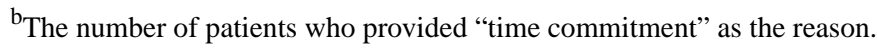

${ }^{\mathrm{c}} \mathrm{N} / \mathrm{A}$ : not applicable. 
Table 4. Reasons given for withdrawal after randomization.

\begin{tabular}{ll}
\hline Reasons & Number of times reason given $(\mathrm{n}=41)^{\mathrm{a}}, \mathrm{n}(\%)$ \\
\hline Study not helpful & $19(46)$ \\
Time commitment & $9(22)$ \\
Uncomfortable with assessments & $3(7)$ \\
Prefers pursuing other treatment & $3(7)$ \\
Feeling better & $3(7)$ \\
Expected counseling & $2(5)$ \\
Other reasons & $2(5)$ \\
\hline
\end{tabular}

a 41 reasons provided by 44 participants who withdrew after randomization (some provided multiple reasons; some provided no reasons).

Figure 2. Distribution of responses to the question "overall, how would you rate the services you received?"(n=121).

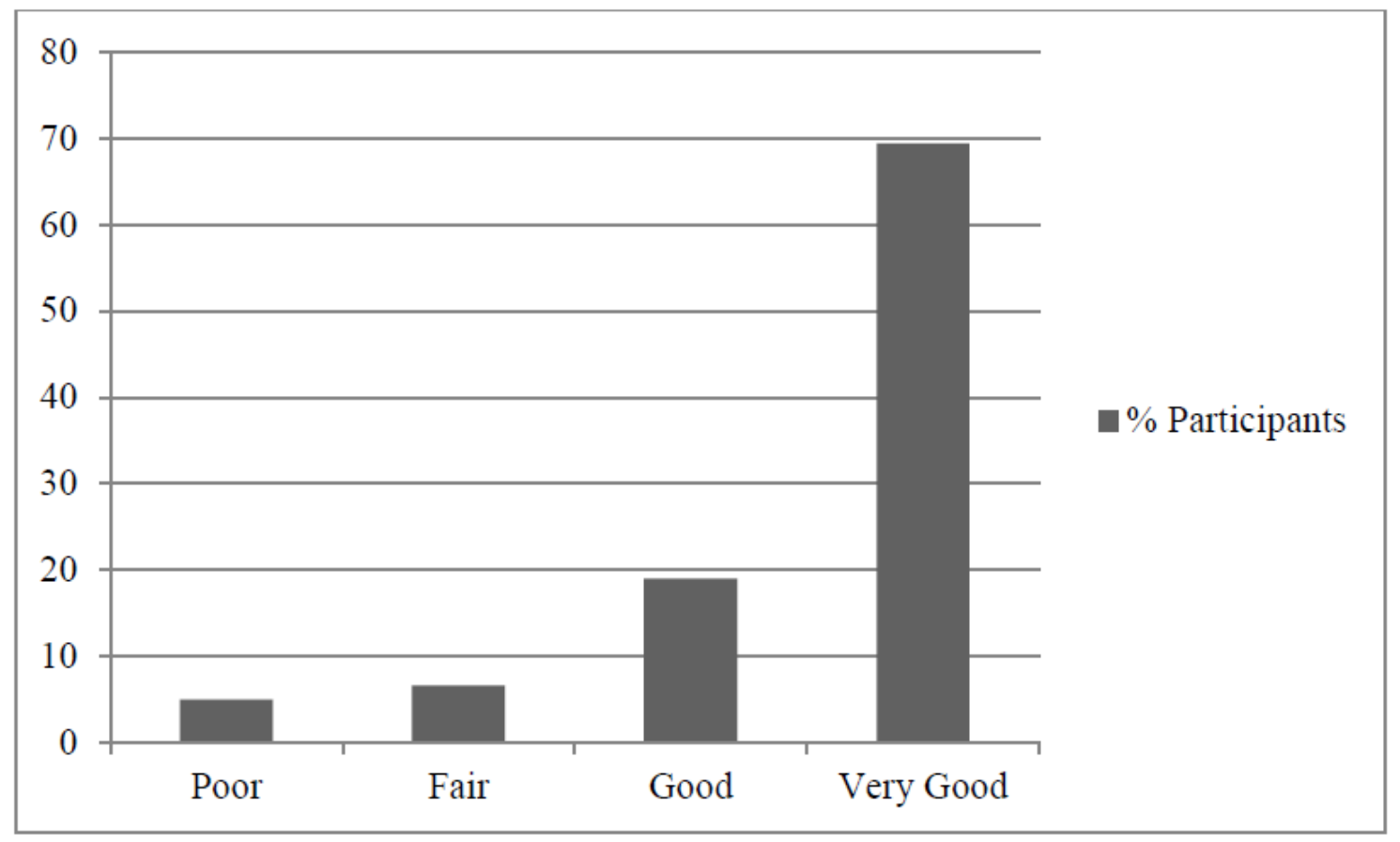

Table 5. Major topics related to use of phone from the satisfaction survey.

\begin{tabular}{ll}
\hline Topics & Number of comments $(\mathrm{n}=45)^{\mathrm{a}}, \mathrm{n}(\%)$ \\
\hline Positive comments & $38(84)$ \\
Accessibility and convenience of calls & $21(47)$ \\
Flexibility & $7(16)$ \\
Privacy and anonymity & $4(9)$ \\
Liked phone calls & $4(9)$ \\
Text reminders & $2(4)$ \\
Negative comments & $7(16)$ \\
Would prefer in-person services & $4(9)$ \\
Barriers associated with telephone use & $3(7)$ \\
\hline
\end{tabular}

a 45 comments provided by 39 participants (some provided multiple comments). 


\section{Discussion}

\section{Principal Findings}

We assessed the acceptability of computer-aided telephone assessments and support for primary care patients with depression, anxiety, and at-risk drinking. Telephone services were highly acceptable, as demonstrated by high consent and retention rates and overall positive feedback. Only a small proportion of referred patients cited the use of telephone as their main reason for declining to participate and none cited this as a reason for withdrawing after randomization.

\section{Comparisons with Prior Work}

Our results are congruent with those of several previous studies that have demonstrated telephone as an effective means of engaging some patients in mental health screening and interventions [9-13,18]. Several of our findings deserve further comment. First, we were unable to reach and engage approximately $10.3 \%(69 / 667)$ of the patients referred to the study despite attempting to call them up to 10 times over a period of 1 month. Similarly, despite multiple attempts, we could not complete the baseline assessment in 6.7\% (32/476) of the participants who consented. Although these rates are low, they illustrate the decreased engagement opportunities of a telephone intervention compared with an intervention embedded in a practice setting. Also, although PCPs were informed about this inability to contact their patients, we do not know what happened to these patients.

Only a small proportion of those who were contacted declined to participate. The main reason cited was the time commitment required to participate in the study. The second reason was a preference for other treatment, typically counseling or psychotherapy. By contrast, only a few specifically mentioned being uncomfortable with telephone assessments and intervention. A few patients also explicitly indicated a preference for speaking with a trained professional. Thus, although lay providers may facilitate access to mental health care by increasing the supply of providers and decreasing costs, they may not be accepted by all patients.

The retention rate was over $80 \%$, higher than the retention rate in most 12-month or shorter randomized studies of mental health interventions [22]. Previous studies of telephone interventions have shown similar high retention rates [9,12,14-17]. The use of cellular phones by almost all participants, in combination with appointment text reminders, may have contributed to the high retention rate because it facilitated participants' availability. Taken together, these results support the acceptability of computer-aided telephone-based mental health support in primary care. Furthermore, our high retention rate in a study in which half of the participants were randomized to a low intensity condition (ie, telephone assessments every 4 months) suggests that frequent calls may not be needed to promote retention. In some prior studies, the retention rate was negatively correlated with the length of the study (as would be expected) and with the frequency of contacts $[9,12,14,15,17]$. This suggests that many patients prefer a shorter time commitment. After randomization, none of the relatively small number of participants who withdrew cited the use of telephone as their reason. The main reported reason was that "participation was not helpful," but about one-fifth did not provide a reason for withdrawal. We did not identify specific characteristics (eg, age, gender, mental health condition) associated with withdrawal from the study (data not shown).

Finally, the satisfaction survey responses were almost universally positive and highlighted several advantages of a telephone intervention. As expected, participants identified accessibility and convenience. Access is particularly important in rural areas where resources are scarce [9]. A telephone intervention can also be used to engage those people for whom driving or other aspects of mobility are issues, such as older adults [9]. Participants also appreciated being contacted promptly and the flexible call times, obviating the need to take time off work or school. Some participants also identified privacy and anonymity as advantages of the telephone intervention. Thus, we believe it helped alleviate the stigma that remains attached to accessing mental health services. Similarly, some participants reported that the relative anonymity of telephone calls made it easier to disclose and discuss sensitive issues such as suicidal ideation, self-harm, or past traumas not previously disclosed to their PCP.

\section{Limitations}

The main limitations are owing to our study not being designed to directly assess the acceptability of the phone intervention. First, some patients declined the referral to the study, and we did not collect the number of, or reasons for, these refusals. Though we believe that most were owing to concerns about participating in a randomized trial, some may have been because of the telephone intervention. Thus, our results may overestimate the acceptability of this type of service. A different study eliciting preference for an in person versus a telephone intervention, followed by randomization to one of these interventions, would be needed to compare the acceptability and adherence to these 2 types of interventions in the general patient population. However, the high retention rate supports the acceptability of the telephone intervention in those who consented to the study. Second, the satisfaction survey was completed during the last assessment and it is possible that we would have obtained less positive feedback from the small number of participants who discontinued the study early.

\section{Conclusion}

Many patients in primary care settings cannot access traditional mental health care. Fully automated interventions (eg, Web-based therapy) offer potential innovative and cost-effective solutions to this problem [23,24]. Although these more advanced technologies are being developed, "plain-old telephone" can be combined with computer-based assessments and support. This approach seems to be highly acceptable to a large number of primary care patients. Furthermore, even when in-person or fully automated services are available, computer-aided telephone-based mental health services may have unique advantages for some subgroups of patients. We envision a future mental health system that optimizes access and quality by integrating multiple modes of service delivery-in person, by phone, and via Web-based and mobile platforms. 


\section{Acknowledgments}

The PARTNERs study was supported by a grant from the CAMH Foundation using funds donated by Bell Canada and the Medical Psychiatry Alliance; the Medical Psychiatry Alliance is a Canadian collaborative partnership between the Centre for Addiction and Mental Health, the Hospital for Sick Children, Trillium Health Partners, and the University of Toronto (all in Ontario, Canada) dedicated to transforming the delivery of mental health services for patients who suffer from physical and psychiatric illness or medically unexplained symptoms. The BHL software used in the study was provided at no cost by Capital Solution Design.

PARTNERs Study Group (collaborators): Mental Health Technician: Adam Whisler; Research Associates: Kyle Fitzgibbon, Eleni Kelly, Alexandra Kubica.

\section{Authors' Contributions}

BHM, AP, and DO conceptualized and designed the study. VG and SZ were the Mental Health Technicians who delivered the intervention. JC conducted structured assessments. DR, AP, and BHM provided supervision to the Mental Health Technicians and Research Associates. SZ, VG and JC analyzed the data and conducted the literature search. SZ and BHM drafted the manuscript. All authors provided critical input and reviewed the final manuscript.

Authors' roles in the PARTNERs Study Group: Principal Investigator: BHM; Project Psychiatrist and Co-investigator: DR; Project Director: AP; Co-investigators: AC, RG, AL, BM, NS; Mental Health Technicians: VG, SZ; Research Associate: JC; Consultant: DO.

\section{Conflicts of Interest}

BM receives compensation from the following: the Department of Psychiatry, University of Toronto, Toronto, Ontario; CAMH, Toronto, Ontario; and the University of Pittsburgh, Pittsburgh, Pennsylvania. He belongs to the Board of Trustees of CAMH, Toronto, Ontario. He currently receives research support from Brain Canada, the Canadian Institutes of Health Research, the CAMH Foundation (funding of the study described in this paper with a gift from Bell Canada), the Patient-Centered Outcomes Research Institute, the US National Institute of Health (NIH), Capital Solution Design Limited Liability Corporation (software used in the study described in this paper), and HAPPYneuron (software used in a study founded by Brain Canada). Within the past 5 years, he has also received research support from Bristol-Myers Squibb (medications for a NIH-funded clinical trial), Eli-Lilly (medications for an NIH-funded clinical trial), and Pfizer (medications for an NIH-funded clinical trial). He directly owns stocks of General Electric (less than Can \$5000).

\section{Multimedia Appendix 1 \\ CONSORT-EHEALTH checklist (V 1.6.1).}

[PDF File (Adobe PDF File), 2MB-Multimedia Appendix 1]

\section{References}

1. Pearson C. Statistics Canada, Contract No. 2015. The impact of mental health problems on family members URL: http:/ /www.statcan.gc.ca/pub/82-624-x/2015001/article/14214-eng.pdf [accessed 2018-02-08] [WebCite Cache ID 6x5flZo2o]

2. Smetanin P, Stiff D, Briante C, Adair C, Ahmad S, Khan M. RiskAnalytica, on behalf of the Mental Health Commission of Canada. The Life and Economic Impact of Major Mental Illnesses in Canadato 2041 URL: https://www. mentalhealthcommission.ca/sites/default/files/MHCC Report Base Case FINAL ENG 0 0.pdf [accessed 2018-02-08] [WebCite Cache ID 6x5gH2zT6]

3. McRae L, O'Donnell S, Loukine L, Rancourt N, Pelletier C. Report summary - Mood and Anxiety Disorders in Canada, 2016. Health Promot Chronic Dis Prev Can 2016 Dec;36(12):314-315 [FREE Full text] [Medline: 27977086]

4. Ratnasingham S, Cairney J, Rehm J, Manson H, Kurdyak P. Toronto, Ontario. Opening eyes, opening minds: The Ontario burden of mental illness and addictions report URL: https://www.publichealthontario.ca/en/eRepository/

Opening Eyes Exec Summary En 2012.pdf [accessed 2018-02-08] [WebCite Cache ID 6x5gZq8hn]

5. Brien S, Grenier L, Kapral M, Kurdyak P, Vigod S. Toronto: Health Quality Ontario and Institute for Clinical Evaluative Sciences. 2015. Taking Stock: A Report on the Quality of Mental Health and Addictions Services in Ontario URL: http:/ /www.hqontario.ca/Portals/0/Documents/pr/theme-report-taking-stock-en.pdf [accessed 2018-02-08] [WebCite Cache ID $\underline{6 x 5 g e 0 r X h]}$

6. Kurdyak P, Zaheer J, Cheng J, Rudoler D, Mulsant BH. Changes in Characteristics and Practice Patterns of Ontario Psychiatrists. Can J Psychiatry 2017 Jan;62(1):40-47 [FREE Full text] [doi: 10.1177/0706743716661325] [Medline: 27550804]

7. Sunderland A, Findlay L. Health reports. Perceived need for mental health care in Canada: results from the 2012 Canadian Community Health Survey-Mental Health URL: http://www.statcan.gc.ca/pub/82-003-x/2013009/article/11863-eng.pdf [accessed 2018-02-08] [WebCite Cache ID 6x5gjgdH2] 
8. Barua B, Fathers F. Fraser Institute. Waiting your turn: wait times for health care in Canada, 2014 report URL: https://www. fraserinstitute.org/sites/default/files/waiting-your-turn-wait-times-for-health-care-in-canada-2016.pdf [accessed 2018-02-08] [WebCite Cache ID 6x5goP48E]

9. Simon GE, VonKorff M, Rutter C, Wagner E. Randomised trial of monitoring, feedback, and management of care by telephone to improve treatment of depression in primary care. BMJ 2000 Feb 26;320(7234):550-554 [FREE Full text] [Medline: 10688563]

10. Oslin DW, Sayers S, Ross J, Kane V, Ten HT, Conigliaro J, et al. Disease management for depression and at-risk drinking via telephone in an older population of veterans. Psychosom Med 2003;65(6):931-937. [Medline: 14645769]

11. Brown RL, Saunders LA, Bobula JA, Mundt MP, Koch PE. Randomized-controlled trial of a telephone and mail intervention for alcohol use disorders: three-month drinking outcomes. Alcohol Clin Exp Res 2007 Aug;31(8):1372-1379. [doi: 10.1111/j.1530-0277.2007.00430.x] [Medline: 17550366$]$

12. McCusker J, Cole M, Yaffe M, Sussman T, Lavoie KL, Strumpf E, et al. A feasibility study of a telephone-supported self-care intervention for depression among adults with a comorbid chronic physical illness in primary care. Ment Health Fam Med 2012 Dec;9(4):257-273 [FREE Full text] [Medline: 24294301]

13. Mello MJ, Baird J, Nirenberg TD, Lee C, Woolard R, Longabaugh R. DIAL: a randomised trial of a telephone brief intervention for alcohol. Inj Prev 2013 Feb;19(1):44-48. [doi: 10.1136/injuryprev-2012-040334] [Medline: 22627778]

14. Pickett YR, Kennedy GJ, Freeman K, Cummings J, Woolis W. The effect of telephone-facilitated depression care on older, medically ill patients. J Behav Health Serv Res 2014 Jan;41(1):90-96 [FREE Full text] [doi: 10.1007/s11414-013-9327-1] [Medline: 23572444]

15. McCusker J, Cole MG, Yaffe M, Strumpf E, Sewitch M, Sussman T, et al. A randomized trial of a depression self-care toolkit with or without lay telephone coaching for primary care patients with chronic physical conditions. Gen Hosp Psychiatry 2016;40:75-83. [doi: 10.1016/j.genhosppsych.2016.02.004] [Medline: 27067224]

16. McCusker J, Cole M, Lambert S, Yaffe M, Ciampi A, Belzile E. Baseline Psychological Treatment Reduces the Effect of Coaching in a Randomised Trial of a Depression Self-Care Intervention. Can J Psychiatry 2017 Dec;62(1):67-72 [FREE Full text] [doi: 10.1177/0706743716648299] [Medline: 27310241]

17. Simco R, McCusker J, Sewitch M, Cole M, Yaffe M, Lavoie K, et al. Adherence to a Telephone-Supported Depression Self-Care Intervention for Adults With Chronic Physical Illnesses. SAGE Open 2015 Mar 03;5(1):215824401557248 [FREE Full text] [doi: 10.1177/2158244015572486] [Medline: 22973420]

18. Rollman BL, Belnap BH, Mazumdar S, Abebe KZ, Karp JF, Lenze EJ, et al. Telephone-Delivered Stepped Collaborative Care for Treating Anxiety in Primary Care: A Randomized Controlled Trial. J Gen Intern Med 2017 Mar;32(3):245-255. [doi: 10.1007/s11606-016-3873-1] [Medline: 27714649]

19. Katzman R, Brown T, Fuld P, Peck A, Schechter R, Schimmel H. Validation of a short Orientation-Memory-Concentration Test of cognitive impairment. Am J Psychiatry 1983 Jun;140(6):734-739. [doi: 10.1176/ajp.140.6.734] [Medline: 6846631]

20. Kroenke K, Spitzer RL, Williams JB. The PHQ-9: validity of a brief depression severity measure. J Gen Intern Med 2001 Sep;16(9):606-613 [FREE Full text] [Medline: 11556941]

21. Wagner EH, Austin BT, Von Korff M. Organizing care for patients with chronic illness. Milbank Q 1996;74(4):511-544. [Medline: 8941260]

22. Begun A, Berger L, Otto-Salaj L. Participant Recruitment and Retention in Intervention and Evaluation Research. New York: Oxford University Press; 2018.

23. Cuijpers P, van Straten A, Andersson G. Internet-administered cognitive behavior therapy for health problems: a systematic review. J Behav Med 2008 Apr;31(2):169-177 [FREE Full text] [doi: 10.1007/s10865-007-9144-1] [Medline: 18165893]

24. Andersson G, Cuijpers P, Carlbring P, Riper H, Hedman E. Guided Internet-based vs. face-to-face cognitive behavior therapy for psychiatric and somatic disorders: a systematic review and meta-analysis. World Psychiatry 2014 Oct;13(3):288-295 [FRE Full text] [doi: 10.1002/wps.20151] [Medline: 25273302]

Abbreviations
BHL: Behavioral Health Laboratory
CAMH: Centre for Addiction and Mental Health
MHT: Mental Health Technicians
NIH: National Institute of Health
PARTNERs: the Primary care Assessment and Research of a Telephone intervention for Neuropsychiatric
conditions with Education and Resources study
PCP: primary care provider
RA: research associate


Edited by J Torous; submitted 26.02.18; peer-reviewed by J McCusker, J Torous; comments to author 06.06.18; revised version received 15.08.18; accepted 05.09.18; published 10.12.18

Please cite as:

Zaheer S, Garofalo V, Rodie D, Perivolaris A, Chum J, Crawford A, Geist R, Levinson A, Mitchell B, Oslin D, Sunderji N, Mulsant BH, PARTNERs Study Group

Computer-Aided Telephone Support for Primary Care Patients with Common Mental Health Conditions: Randomized Controlled Trial

JMIR Ment Health 2018;5(4):e10224

URL: http://mental.jmir.org/2018/4/e10224/

doi: $10.2196 / 10224$

PMID: 30530461

(CSalaha Zaheer, Vanessa Garofalo, David Rodie, Athina Perivolaris, Jenny Chum, Allison Crawford, Rose Geist, Andrea Levinson, Brian Mitchell, David Oslin, Nadiya Sunderji, Benoit H. Mulsant, PARTNERs Study Group. Originally published in JMIR Mental Health (http://mental.jmir.org), 10.12.2018. This is an open-access article distributed under the terms of the Creative Commons Attribution License (https://creativecommons.org/licenses/by/4.0/), which permits unrestricted use, distribution, and reproduction in any medium, provided the original work, first published in JMIR Mental Health, is properly cited. The complete bibliographic information, a link to the original publication on http://mental.jmir.org/, as well as this copyright and license information must be included. 